\title{
Palavra de escritor
}

Cecilia Almeida SALLES

Pontifícia Universidade Católica de São Paulo

Resumo: $\mathrm{O}$ artigo apresenta um estudo de crítica genética, sob a perspectiva da semiótica de linha peirceana, sobre o processo de construção do livro Não Verás País Nenbum de Ignácio de Loyola Brandão. Estará sendo dada ênfase aos mecanismos criativos do escritor em seu trabalho com a palavra.

Abstract: The article presents a study on genetic criticism, with the theoretical
support of the peircean semiotics, about the process of construction of the
book Não Verás País Nenbum written by Ignácio de Loyola Brandão. Having as
the starting point of the analysis the writer's work with verbal language, his
creative procedures will be emphasized.

Resumen: El artículo presenta un estudio de crítica genética, bajo la perspectiva de C.S. Peirce, sobre el proceso de construcción del libro Não Verás País Nenbum, escrito por Ignácio de Loyola Brandão. Tendrá como el punto de partida la observación de los mecanismos de creación del referido escritor en su trabajo con la palabra.

\section{Introdução}

Este artigo estará apresentando um estudo de crítica genética, que tem como objetivo primeiro a compreensão do processo de construção de obras artísticas. A ênfase, aqui, será dada à literatura; de modo mais específico, estarei abordando a relação do artista com sua matéria, ou seja, a relação do escritor com a palavra.

SIGNUM: Estud. Ling., Londrina, n. 5, p. 255-274, dez. 2002 
Como ponto de partida para esta discussão, é necessário fazer algumas reflexões sobre o ato criador. Os estudos genéticos se multiplicaram e muitas afirmações referentes aos processos estudados passaram a fazer parte de aspectos tácitos, para a entrada em qualquer nova pesquisa. No âmbito do trabalho com a palavra lidamos, no mínimo, com dois desses pressupostos: a preocupação com o aperfeiçoamento do texto e impossibilidade de se pensar o trabalho com a palavra de modo isolado.

Todo escritor (aliás, todo artista) re-trabalha seu texto à exaustão: insatisfação permanente e sensação de que sua matéria prima precisa sempre ser mais burilada não são peculiaridades do escritor que escolhemos para estudar. Adicionar, cortar e substituir são instrumentos de trabalho de todos aqueles que lidam com a palavra. Escrever é ler e re-escrever: é o caráter retroativo de todo processo criador. A revisão chega a ser prevista, como vemos em uma anotação de Loyola: "Preciso de bons sinônimos. Na primeira re-escritura". Em outro momento, ele diz: "Não gostei do que escrevi hoje. Falta consistência. Vou deixar dormir, depois volto".

Algo é constante nos relatos dos escritores, revisão é sinônimo de esforço: "Parece tão fácil escrever secamente, descarnadamente. E dá um trabalho. É preciso ler atentamente uma, cinco vezes, 10 tem sempre um acerto possível.", observa o escritor.

Tendo em mente o segundo pressuposto, o importante é conhecer a relação do artista com a matéria no ambiente daquele processo específico, que abarca um amplo espectro de limites, restrições e critérios de decisão. Cada alteração contém princípios estéticos e éticos do escritor que envolvem tipo de literatura buscada, escolha do meio de expressão (romance, conto, poema...), tom do texto, características dos personagens que, por sua vez, se inter-relacionam, só para citar alguns exemplos. Entramos, aqui, na complexidade do universo da re-escritura.

O que estou enfatizando é que as mudanças lingüísticas precisam ser analisadas dentro deste contexto mais amplo: nenhuma decisão pode 
ser vista de modo isolado, se o crítico busca um estudo genético. As alterações sofridas pelo texto só vão ter poder de oferecer algum tipo de explicação sobre o processo do escritor, se compreendermos em nome do que são feitas. Muitas dessas informações só aparecem a partir de um amplo e incansável estabelecimento de relações entre as mudanças que os rascunhos mostram. Por outro lado, essas possibilidades de obra devem ser relacionadas com outros documentos como anotações, diários, fichas etc.

No caso do processo de Não Verás, eu tinha em mãos diferentes fontes de informação ou documentos do processo. Diários que mostram, de modo geral, um trabalho eminentemente metalingüístico: discussões do escritor com ele mesmo. Anotações que não são a escritura propriamente dita, mas estão mais perto da obra do que dos critérios que direcionam a ação do escritor: já são encontrados textos que podem fazer parte da obra. Rascunhos que já podem ser obra e deixam, assim, emergir a ação literária propriamente dita: é o fluxo da escritura.

As reflexões do escritor e o estabelecimento de critérios para suas decisões, encontrados nos diários e anotações, direcionam a ação dos rascunhos. Esse fato reflete, mais uma vez, o caráter de dependência entre os diferentes documentos.

Estarei apresentando algumas questões que envolveram o trabalho de Ignácio de Loyola Brandão com a palavra, ao longo da produção de Não Verás País Nenhum. Para a organização de tal debate, lanço mão de uma das conclusões que o acompanhamento deste processo me permitiu chegar. Percebe-se que há critérios dados e outros conquistados pela obra em construção. Vamos compreendê-los melhor.

\section{Critérios dados}

Um desses critérios diz respeito a normas pré-estabelecidas: há alterações que são, claramente, feitas em obediência a regras da língua 
portuguesa: ajustes de regência, concordância verbal e ortografia, que podem ser considerados correções de erros.

\section{Sinônimos}

Ainda no campo dos critérios dados, o escritor busca diversidade semântica. Essa variação é estipulada por normas do discurso escrito em língua portuguesa. Como todos sabemos, a repetição é sempre radicalmente evitada. Loyola demonstra esta preocupação o que o leva a buscar sinônimos e anotar em seu diário: "Usando demais [...]. Preciso urgente de bons sinônimos". "Excesso de uso de uma palavra - NÃO. Sinto a presença. Quando a gente sente a presença de uma palavra ou ela está mal empregada ou existe excesso".

Listagens de sinônimos ou lembretes de necessidade de encontro de sinônimos observadas nas anotações do escritor são índices dessa tentativa de fugir da repetição:

$$
\begin{aligned}
316-\text { Amargura }= & \text { aflição } \\
& \text { angústia } \\
& \text { aspereza } \\
& \text { azedume } \\
& \text { desgosto } \\
& \text { mágoa } \\
& \text { pesar } \\
& \text { tormento } \\
& \text { tristeza } \\
& \text { mortificado }
\end{aligned}
$$

No diário de trabalho, Loyola comenta que demorou em busca de um bom sinônimo para amargura, adiciona a lista da anotação 316 e chega à conclusão que nenhum lhe serve. Ele faz ainda comentários sobre as 
dificuldades do encontro de sinônimos, que serão apresentados mais adiante, quando discute a escolha de palavras em consonância com características dos personagens.

Não Verás caminhava para repetidas menções de períodos marcantes do passado, na anotação 566 o escritor fala da ÉPOCA DAS TRAMITAÇÕES MERCANTIS. São características da sociedade brasileira nos tempos em que o livro foi produzido (1978-1981), que se transformam em lembranças críticas dos personagens. ${ }^{1}$ Logo após a apresentação dessa ÉPOCA, Loyola anota:

\section{SINÔNIMOS PARA ÉPOCAPeríodo}

Decurso

Estação

Temporada

Era

Fase

Etapa

Ciclo

Circuito

Idade

Vez

Os rascunhos e a obra nos mostram que a palavra escolhida foi era.

É interessante observar que os campos semânticos pesquisados pelo escritor aparecem, muitas vezes, tanto no diário como nas anotações, como vemos nos exemplos que seguem:

\footnotetext{
${ }^{1}$ A anotação completa é: ÉPOCA DAS TRAMITAÇÕES MERCANTIS. O governo aprovava tudo o que queria através da compra de deputados, administradores, enfim de todo e qualquer servidor público de que dependesse a lei ou o andamento dos processos.
}

SIGNUM: Estud. Ling., Londrina, n. 5, p. 255-274, dez. 2002 
Tédio/Aborrecimento

Desgostoso-nojo-monótono-insípido-tristeza-desconsolo (Diário)

Sinônimo para irritação. Encher-raiva-aborrecer (Anotações)

Isto demonstrando a importância desses campos para a narrativa em curso, que estão, certamente, relacionados ao clima geral do universo em criação, onde tédio, amargura e irritação envolvem toda a sociedade .

\section{Artigos}

Encontramos ainda uma outra fonte de rasuras que merece atenção permanente por parte do escritor. É bastante interessante analisar sua quase obsessão pelo corte de artigos definidos e indefinidos e de pronomes demonstrativos e possessivos. Em um primeiro momento, poderíamos justificar esses cortes pela formação jornalística de Ignácio de Loyola. O texto econômico do jornal poderia deixar marcas na literatura do escritor, que pertence a uma geração de jornalistas que viveram o auge da repressão militar e que foram para a literatura diante da impossibilidade de se fazer um jornalismo digno. Encontraríamos na ausência de artigos e alguns pronomes uma literatura enxuta. Sem descartar essa hipótese, vamos adiante na análise desses cortes.

Em suas anotações, Loyola afirma que artigos são "desnecessários". Ele acredita que a supressão de artigos dá "melhor sonoridade e fluência" ao texto. Estou cortando todos um que vejo pela frente, o um é desnecessário". Ou ainda "Esbarro em muitos isso, esse, essa. Que terrível". Diz, em outro momento, buscar "um estilo econômico, bastante simples e despojado". Loyola lutou por um Não Verás enxuto, onde artigos e alguns pronomes, sendo desnecessários segundo seus critérios, deveriam ser eliminados. Vale lembrar que outras obras do escritor, cujos processos de construção venho acompanhando, são alvo deste mesmo procedimento. 
Caminhando ainda na discussão desses cortes específicos, encontramos o conselho de Mário de Andrade (1982, p. 25) para Carlos Drummond: "Aliás procure evitar o mais possível os artigos tanto definidos como indefinidos. Não só porque evita galicismo e está mais dentro das línguas hispânicas, como também porque dá mais rapidez e força incisiva pra frase". Artigos e pronomes possessivos são vistos como "berenguendés que castram a frase".

Indo para trás no tempo e nos afastando no espaço, mas continuando na língua portuguesa, Carmela Nuzzi (1979, p. 412) observa que "o artigo indefinido e o pronome demonstrativo eram algumas vezes substituídos pelo artigo definido ou suprimidos", nas diferentes versões de A Ilustre Casa de Ramires de Eça de Queiróz,', como em:

E, o Pereira, nesse tempo, um colono, E, o Pereira, nesse tempo, colono, um servo, só falava ao seu senhor de servo, só abordava ao seu senhor de joelhos ... joelhos ...

Outras gerações e outros princípios estéticos, mas preocupações semelhantes no que diz respeito a essas supressões.

Poderíamos dizer que essas eliminações fazem parte de exigências do discurso escrito em língua portuguesa. Como as primeiras versões dos textos sempre trazem esses excessos, acreditamos que a oralidade tenha um peso bastante grande nessas primeiras tentativas de texto. Os cortes serão certamente feitos, isto é, o texto escrito não comporta esses "berenguendés", mas o uso nas primeiras versões parece ser incontrolável.

Por um ou todos esses motivos apresentados encontramos nos rascunhos de Loyola uma grande quantidade de cortes como estes:

${ }^{2}$ Cf. Salles, Cecilia A . "Faço muito Ramires". Em A Ilustre Casa de Ramires. Cem anos. São Paulo: EDUC, 2000.

SIGNUM: Estud. Ling., Londrina, n. 5, p. 255-274, dez. 2002 
Vamos fazer uma surpresa.

Não deixa passar o calor.
Vamos fazer surpresa.

Não deixa passar calor.

Pronomes possessivos e demonstrativos são também eliminados mas em número bem menor do que os artigos. As primeiras versões já são produzidas com marcante escassez desses pronomes.

Nos afastamos, agora, do trabalho de Loyola com a língua a partir de exigências pré-determinadas e começamos a nos aproximar mais da construção de um Não Verás a partir de características dadas pelo escritor, o que é, na verdade, de mais interesse para a compreensão de seus mecanismos criativos.

\section{Critérios conquistados}

Neste ambiente de conquistas, desconhecidas no início do percurso, são feitos ajustes de acordo com normas não pré-determinadas, até a descoberta do texto que satisfaça o escritor. Sob esse ponto de vista, critérios e obra são elaborados ao longo do processo, ou seja, o percurso criador é responsável pela construção de leis próprias.

É neste sentido que discutimos a verdade artística ${ }^{3}$, que surge da própria trama da construção da obra e que, por estar inserida na continuidade do processo, não é absoluta nem final mas sempre potencialmente mutável. Verdade que emerge da obra, sob o comando do grande projeto do artista.

O artista, ao construir uma nova realidade, vai desatando-a da realidade externa à obra. Pois somente ao libertar-se da realidade, a força criadora pode agir segundo suas próprias leis, em sua qualidade produtiva. Leis que passam a reger aquela obra e que geram uma multiplicidade de escolhas. Decisões são tomadas como necessidades daquela obra. No processo de fabricação de uma obra, é construída sua legalidade interna, à qual o artista é o primeiro a ser submetido (Pareyson, 1989).

\footnotetext{
${ }^{3}$ Cf. Salles, Cecilia A . Gesto Inacabado: Processo de criação artística. 2. ed. São Paulo: Annablume, 2001.
} 


\section{Tendências se definem}

\section{Mais cortes}

Continuando ainda no campo dos cortes, entramos, agora, na discussão das modificações regidas por auto-exigências do escritor. $\mathrm{Na}$ busca por seu "texto descarnado", Loyola corta pronomes/sujeito, pronomes de tratamento e conjunções (principalmente a adversativa mas). Alguns verbos são também considerados "desnecessários": "Gosto de eliminar os verbos. Parece que a frase fica mais consistente. Ao mesmo tempo mais leve".

Vejamos alguns exemplos:

Eu nunca me lembrava. Nunca me lembrava.

O senhor pensa que é isso para todo mundo? Pensa que é isso para todo mundo?

Não sei como mas enxergam tudo Não sei como enxergam tudo

Está quente demais. Quente demais.

É melhor viver um dia somente Melhor viver um dia somente

Os cortes não param aqui, Loyola anota em seu diário: "Descobri que o adjetivo atrapalha uma frase. Quanto menos adjetivo você usar muito melhor para sua frase. Quanto mais substantivo você puser é muito melhor".

Não se pode deixar de fazer a relação entre a eliminação de adjetivos, locuções adjetivas e advérbios e a escassez de descrições encontrada em Não Verás, que é assim explicada em uma anotação: "não descrevo fisicamente os personagens. De vez em quando solto um detalhe. Acredito que descrições físicas são desnecessárias. O leitor sempre forma em sua cabeça um tipo que ele julga ser o correto. Souza é brasileiro. Basta isso”". 
Essa decisão de evitar descrições está associada a outro critério que o processo adquire ou conquista: tornar a narrativa mais geral. Enquanto Souza (o personagem principal) passa a ser um brasileiro qualquer, o tempo torna-se indefinido e Loyola decide eliminar o uso de gíria e os trechos datados, como o início da loteria esportiva e das cadernetas de poupança.

“... a gíria tem uma data determinada e eu não podia usá-la no livro, que se passa muitos anos a frente? ... Terminei utilizando, mas o mínimo possível, uma vez que a história se passa no futuro", anota Loyola em seu diário.

Retornando à anotação anterior, nos defrontamos com outro aspecto que envolve muitas decisões do escritor: a comunicação com o futuro leitor. Esta preocupação comunicacional fica aparente quando ele conta com a imaginação do leitor, duvida da eficácia de uma palavra por ele inventada, por não parecer convincente (para quem ?) e na simples adição de um pronome possessivo (tão evitado em outros momentos) para não haver mal entendido.

\section{Adelaide trouxe o enxoval. Adelaide trouxe o sen enxoval.}

Loyola temia não deixar claro para o leitor que não era do enxoval da criança e sim do de Adelaide que ele estava falando. É desnecessário dizer que o escritor sabia que ele se referia ao enxoval de Adelaide.

Para continuar a discussão sobre o processo criador como um espaço de conquista de critérios de decisão, é necessário falar sobre a grande tendência deste processo.

Em um outro artigo ${ }^{4}$, discutindo a construção da cidade de Não Verás, apontei que Loyola buscava relatar a destruição do homem causada

\footnotetext{
${ }^{4}$ Salles, Cecilia A. "A planta da cidade: uma leitura genética de Não Verás País Nenhum". Em Cadernos de Literatura Brasileira do Instituto Moreira Salles, $\mathrm{n}^{\circ}$ 11. São Paulo: Instituto Moreira Salles, 2001.
} 
pelas condições inóspitas da sociedade e da cidade. Ele menciona muitas vezes este intuito de fazer um "retrato de um apocalipse". Em uma entrevista na época em que escrevia Não Verás, disse:

Essa é minha tentativa na literatura - é modificar, é estourar com a cabeça das pessoas e eu procuro fazer isso continuamente. A gente escreve para provocar reação. Não Verás é uma outra tentativa de jogar uma bomba na cabeça do leitor. Provocar o terror na cabeça das pessoas. Penso mostrar a confusão geral que se estabelece e termina por levar ao caos geral, com conseqüências terríveis.

No andamento do processo, ele decide apresentar para o leitor seu mundo imaginado em estado maior de destruição do que aquele pensado no início. Como conseqüência, o clima torna-se mais e mais tenso. Toda essa profusão de cortes gera um texto mais intenso e veloz, que reflete, no modo de narrar, esta sua decisão.

\section{Apocalipse mais próximo}

Foram observadas outras mudanças nos rascunhos, que mostram as conseqüências desta alteração da rota inicialmente vislumbrada. Há mudanças significativas na caracterização de Souza e da sociedade na qual vivia. Assim, "Souza conheceu os pequenos subornos" nos primeiros rascunhos; e depois "Souza aderiu aos pequenos subornos". A "água cara" é substituída por "água difícil para o povo" ${ }^{\circ}$. "almoço motivo de conversa" torna-se o "almoço fuga do trabalho". A "espera de Adelaide no corredor do prédio para se abrigar do calor" passa a ser a "espera por medo"

\footnotetext{
${ }^{5}$ Esta mudança gera uma grande pesquisa do escritor sobre reciclagem de urina.
} 
A "televisão: uma forma de revolta" é substituída por "televisão vigiada pelo governo". Essa substituição, como outras, é um exemplo de que Loyola foi tornado o governo mais totalitário. Essa alteração no conteúdo geral levou à adição de um parágrafo no qual este maior poder fica evidente: dá detalhes sobre o trabalho dos helicópteros do governo na caça aos camelôs, substituindo uma simples caracterização dos camelôs.

A definição do tom ou atmosfera da narrativa que, segundo o autor, deve ser oferecida ao leitor no início do livro (o que não corresponde ao início do processo de escritura propriamente dito) está também relacionada ao aumento de tensão mencionado anteriormente. É assim apresentada no diário:

Acabo de encontrar um bom início, bastante mais forte a meu ver. Vou iniciar pelo cheiro nauseabundo. Claro, uma sociedade rodeada de cadáveres, de lixo, bosta, cheira mal. Assim já dou a atmosfera que cerca os personagens, introduzo o leitor no clima. E pesquisando encontrei uma bela e violenta palavra para iniciar: MEFÍTICO.

O escritor vive uma dúvida durante o processo, pensa em cortar essa introdução ao espaço degradante e entrar diretamente na ação. Há uma intensa mobilidade nos rascunhos desse primeiro segmento ${ }^{6}$. Acha, em determinado momento, que a palavra mefítico é inadequada.

No texto publicado, no entanto, vemos que foi decidido introduzir o leitor ao tom geral da narrativa e a primeira palavra usada é mefítico, por talvez se adequar agora ao clima sufocante e podre que o processo impôs à narrativa. Encontramos ecos para essa decisão na seguinte anotação do escritor: "A palavra tem que se ajustar ao clima da situação". Embora não diga respeito à mefítico, especificamente, tem natureza de comando geral.

\footnotetext{
${ }^{6}$ Nome que o escritor dá aos capítulos do livro.
} 
A pontuação de Não Verás sofre também uma série de modificações. Há uma forte tendência de substituir vírgulas e ponto e vírgulas por pontos, isto é, pausas são transformadas em cortes.

Acompanhemos alguns exemplos:

O dia é bem vivido, cada hora...

O dia é bem vivido. Cada hora...

A noite, o corpo está lá; era manhã...

A noite, o corpo está lá. E na manhã...

A repetição dessas mudanças à exaustão gera uma narrativa elíptica com constantes e ríspidos cortes no fluxo das sentenças. Trata-se da passagem de um discurso contínuo para um discurso descontínuo, que reflete o texto rápido e descarnado no qual Não Verás vai se tornando. E assim o ritmo do texto se acelera mais, indo em auxilio da maior intensidade que o clima da narrativa ganha.

As metas ou tendências que o escritor estabeleceu para sua obra apresentam-se vagas no início do percurso mas encontram estado de maior definição à medida que o processo avança. Suas reflexões e o próprio texto, que vai sendo produzido e avaliado, fazem com que rumos ganhem contornos mais nítidos e alterações sejam feitas, como vimos, em nome de uma adequação a estas novas definições.

\section{Leis se consolidam}

\section{Vocabulário do livro}

Dando continuidade ao acompanhamento do processo de construção de Não Verás, assistimos o surgimento de leis móveis que passam a reger algumas alterações que os rascunhos recebem. $\mathrm{O}$ escritor, por exemplo, anota em seu diário, ao refletir sobre o uso da palavra mefítico: "Achei também que era demais. Ela não tem nada a ver com o vocabulário do livro, bastante simples despojado. Troquei por um pavoroso". 
É importante aqui destacar a existência de um “vocabulário do livro".

\section{Vocabulário do personagem}

Neste mesmo contexto mas caminhando em direção de uma maior especificidade, o escritor anota: "Preciso encontrar um tom diferente na fala de diferentes personagens".

$\mathrm{Na}$ procura por sinônimo para amargura (já mencionada anteriormente), ele constata que "o problema de sinônimo é curioso. Não é simples troca de palavras. Não é substituição. Exigem um pensar grande em cima de cada sinônimo". É neste momento que re-aparece a escolha de um sinônimo ajustando-se "ao estado de espírito do personagem" e auxiliando a "o interior do personagem".

Esta preocupação torna-se mais marcante na caracterização de Souza e de sua mulher Adelaide: "Souza deve ter um tipo de fala próprio. A mulher também. Posso fazer essa diferença surgir através dos conceitos que os personagens emitem". Palavras usadas e modos de pensar se unem na tentativa de encontrar uma voz singular.

Loyola enfrenta dois problemas que refletem este critério de escolha lexical: o uso de gíria e de palavrão. Podemos observar que as decisões relativas à eliminação de gíria encontram duas justificativas: tentativa de eliminar tudo que determinasse tempo (já comentada) e agora ajuste ao personagem. Vejamos como ele enfrenta esses obstáculos lingüísticos em seu diário:

... não quero usar gíria ... por que o meu preconceito contra gíria? Ou seria um contra-senso colocar na boca de Souza, cinquentão e universitário uma gíria? ... [...] Noto que até aqui não usei um só palavrão. Porque a ação não exige e o personagem não é dado a falar. 
Ainda no caminho de caracterização de Souza, Loyola, em certo momento do diário, diz usar de vez em quando palavras de uma geração mais velha, como "que diabos" e "impertinente": "Acho que ajuda a dar linha a Souza, a marcá-lo".

Vemos, portanto, uma relação dialética: personagem determinando a escolha lexical (gíria, palavrão) e a escolha lexical determinando o personagem "linguagem antiga".

Não há dúvida de que a palavra e sua conseqüente seleção têm um peso imenso no processo deste escritor (como de muitos outros). O trabalho no campo semântico é, sem dúvida, maior do que no sintático. É interessante observar, ainda, que a obra assimila e explicita esse critério lexical, adquirido por seu processo de construção. Souza se conscientiza e é conscientizado por outros personagens do uso dessa linguagem antiga. Loyola e Souza se confundem nessa preocupação com a escolha de palavras:

Recatada. Busquei a palavra na pré-história. Cada uma! Um calor destes, gente morrendo, poeira pavorosa, o sol rachando cuca e eu me excitando e ainda sacando palavras como recatada. Se Adelaide ouvisse ficaria com raiva. Também, não encontro outra para definir o seu jeito. (Loyola, 1982, p. 335)

\section{Trechos não cabem}

Ainda no campo das leis que consolidam ao longo do processo, encontramos justificativas para cortes de trechos já redigidos por não caberem ou não se encaixarem naquela obra, que tomava formas e contornos mais definidos.

Os apontamentos do diário que discutem a eliminação dos trechos da "Barreira particular à margem das reservas" e do "Holocausto da maçã", nos auxiliam na observação destas exigências da obra em criação 
Barreira particular à margem das reservas

Numa das últimas leituras sobre o original considerado definitivo, notei que havia qualquer coisa estranha, que amarrava o capítulo. Havia um salto na ação ... O episódio era postiço, estava solto, não se ligava... Procurei algum lugar onde pudesse encaixá-lo, sintetizado. No entanto, nesta altura, o romance estava redondo, fechado. Qualquer tentativa poderia provocar rupturas.

\section{Holocausto da Maçã}

Não havia justificativa, não se encaixava. Também não se projetava pára frente, não se ligava a contexto nenhum. (negritos meus)

\section{Critérios ideológicos}

Há também uma clara tendência de consolidação de critérios ideológicos, ao longo do processo. Neste campo encontramos o caminhão de lixo "amarelo e vermelho" sendo substituído por caminhão "amarelo e verde". Há outras tantas substituições onde a relação "país imaginado" e o Brasil da ditadura militar fica mais estreita, à medida que o sistema vai adquirindo mais e mais poder.

Sutis substituições no uso de letras minúsculas por maiúsculas vão redefinindo o poder dos órgãos estatais, por exemplo: rádio geral por Rádio Geral; zona restrita aos divertimentos por Zonas Restritas aos Divertimentos; isolamento por Isolamento.

\section{Regularidade da revisão}

Loyola deixa, também, transparecer a idéia de que a revisão passa a ser um processo regular, ganha leis, de tal modo que acredita poder delegar 
poder para outra pessoa. Em certo momento do diário, seu conceito de revisão é amplamente explicitado por estar o escritor temendo não poder, por algum motivo, terminar seu livro: "Se me acontecer alguma coisa, o livro está meio pronto. Como existe a terceira versão do segmento 1, fica depois mais fácil de alguém acertá-lo". E ele chega a indicar um jornalista que poderia fazer esse trabalho.

\section{Revisão e edição}

A revisão do texto caracterizada pelas adições, substituições e principalmente cortes, em alguns momentos, ganha características de edição, como aquela pela qual os copiões do cinema passam. Loyola fala dessa montagem nos diários:

Passa toda uma seqüência intermediária angustiante. Preciso passar esta seqüência mais para o fim, de tal modo que ele simplesmente não consiga voltar para casa.

Na página 52, fiz uma montagem, porque cortei um largo trecho. Toda aquela viagem caiu fora. Remontei.

Os rascunhos mostram esse mecanismo utilizado com bastante freqüência em diferentes níveis: parágrafos ou trechos maiores.

O caso do texto sobre o moto-contínuo de Sebastião Bandeira, por exemplo, foi produzido originariamente como uma longa narrativa, vinda de muitas anotações mas aparece na obra texto publicado de forma fragmentada. Passou, assim, por este processo de montagem.

Em outro artigo ${ }^{7}$, dei especial destaque ao embate entre otimismo e pessimismo que o escritor enfrentou na construção de Não Verás. Neste

\footnotetext{
${ }^{7}$ Cf. Salles, Cecilia A . "A planta da cidade: uma leitura genética de Não Verás País Nenbum". Em Cadernos de Literatura Brasileira do Instituto Moreira Salles, $n^{\circ}$ 11. São Paulo: Instituto Moreira Salles, 2001.
}

SIGNUM: Estud. Ling., Londrina, n. 5, p. 255-274, dez. 2002 
ambiente, surgem duas pontas de esperança que podem ou não vir a ser a promessa de vida futura da cidade: um pequeno arbusto saindo do chão gretado e o cheiro molhado pressagiando chuva.

Loyola reflete muito sobre o uso desses recursos narrativos que, sem dúvida, têm um papel relevante em sua crença na sobrevivência do homem, ou seja, a visão otimista. Naquele clima sufocante, o surgimento de uma pequena planta e a simples possibilidade de chuva representam formas de vida - pontas de esperança de uma não-destruição ou de uma possível reconstrução. Usar um ? Outro? Os dois ? Onde ? Estas questões ocupam, por algum tempo, o escritor.

Ele pensa, em determinado momento do processo, ter chegado ao fim do último segmento: "E fechei com a promessa de chuva". Mas esta escolha não o satisfaz.

Mais tarde é encontrada uma forma literária de lidar com o conflito dos desejos. E aqueles dois "detalhes" narrativos que representariam a continuidade da cidade aparecem, em meio ao tom delirante que a narrativa adquire pulverizadas no último segmento. É importante destacar que as pontas de esperança chegam à obra mas depois de passarem também por um processo de montagem.

Este mesmo mecanismo alcança o nível morfológico. Há uma grande discussão nos diários sobre a possibilidade de cunhagem de palavras. Isto fica claro na busca de uma palavra para definir o governo e de sinônimos para árvore.

"Não estou gostando da palavra sistema para definir governo. Vou pesquisar outra, mas tem que ser forte”. A partir dessa constatação, assistimos, no diário, a toda uma pesquisa que parte dos sinônimos: "Regime $\rightarrow$ Domínio $\rightarrow$ Dieta $\rightarrow$ Ordem...”. A procura vai para tipos de sistemas: "Sistema artificial, sistema conservativo...". E chega ao significado que a palavra deve carregar: "Algo ligado a Poder + Orgasmo". Daí a tentativa de criação de uma palavra a partir do que ele chama de símbolos - orgia, orgasmo e orgulho - associados a poder. 
Ele faz várias tentativas mas não chega, naquele momento, à palavra procurada. No dia seguinte, busca a solução para o "grande problema" que "é a ausência de sinônimos para árvores. Os pouquíssimos que existem não são utilizáveis". Após a listagem desses poucos, ele adiciona "além do mais, são feios". Daí surge uma idéia: "Talvez eu pudesse criar palavras". Há uma justificativa para essa possibilidade: "a ação se passa dentro de alguns anos". Mas a possibilidade é rejeitada: "mas prefiro utilizar a língua atual" porque "acho que nem conseguiria criar palavras convincentes. Muita pretensão minha: criar palavras".

Loyola não cria, realmente, nenhuma palavra para definir governo, (usa esquema) nem para substituir árvore. No entanto, palavras novas surgem no decorrer do processo. Nas primeiras versões encontramos técnicos, depois tecnocratas e por fim militécno. Processo semelhante é observado com a palavra civiltar. Nascem, portanto, novas classes sociais na montagem de classes existentes: militar/ técnico e militar/civil. A decisão contundente pela não criação de palavras acaba sendo revista e o poder dos militares é assim reforçado pelos dois novos conceitos que aparecem nas montagens.

\section{Algumas conclusões}

Pudemos observar três procedimentos criativos marcantes neste longo percurso de manipulação da palavra.

No início, a obra pode ser tudo, seleções levam à definição de normas internas ao processo, no âmbito do projeto poético do artista. Muitos ajustes são, portanto, feitos enquanto alguns desses alicerces da obra são estabelecidos $\mathrm{O}$ processo passa, em determinados momentos, a se autoreger quando cria suas leis internas. $\mathrm{O}$ escritor obedece, assim, normas que foram por ele mesmo estipuladas. A construção da obra está associada, sob este ponto de vista, à conquista de critérios, alguns mais pontuais, outros que se consolidam como princípios gerais mais abrangentes. 
Há uma clara exacerbação de cortes que atingem artigos, pronomes, verbos, adjetivos, orações subordinadas e coordenadas. Trata-se de uma escolha que é levada ao seu extremo. O uso hiperbólico de cortes gera um texto "descarnado", enxuto, intenso e rápido que dialoga de modo explícito com o clima de crescente tensão, que a obra vai adquirindo.

O processo de montagem, utilizado pelo escritor nos níveis diferentes da palavra, do parágrafo e do segmento, manifesta-se com um recorrente e poderoso recurso criativo. Quando a revisão torna-se edição, novas relações são estabelecidas. Os resultados das montagens agradam o escritor que decide levá-los para a obra que será entregue para o público

$\mathrm{Na}$ relação de Ignácio de Loyola com a palavra, vimos o enfrentamento de normas da língua e a exploração de suas possibilidades semânticas, sintáticas e discursivas. Tudo isso acontece em um percurso cujos rumos vão se definindo: fenômeno inerente à visão de processo sem tendências pré-definidas - visão de criação como uma aventura em direção ao quase desconhecido.

É na quebra de limites e na conquista de critérios de escolhas em nome da obra em construção que a função de escritor é exercida com maior intensidade.

\section{Bibliografia citada}

ANDRADE, Mário de. A lição do amigo. Rio de Janeiro: José Olympio, 1982.

BRANDÃO, Ignácio de Loyola. Não verás país nenbum. 4. ed. Rio de Janeiro: Codecri, 1982.

NUZZI, Carmela. Análise comparativa de duas versões de "A Ilustre Casa de Ramires” de Eça de Queiroz: Porto: Lello \& Irmão - Editores, 1979

PAREYSON, Luigi. Os problemas da estética. São Paulo: Martins Fontes, 1989. 